\title{
Morphometric differences in populations of Nebria kratteri Dejean \& Boisduval, 1830 from two old forests in Calabria (Coleoptera, Carabidae)
}

\author{
Federica TALARICO ${ }^{1, *}$, Antonio MAZZEI ${ }^{1}$, Carmen GANGALE $^{1}$, Giorgia SCRIVANO ${ }^{2}$, \\ Pietro BRANDMAYR ${ }^{2}$ \\ ${ }^{1}$ Natural History Museum and Botanical Garden, University of Calabria 87030, Italy - federica.talarico@unical.it; \\ antonio.mazzei@unical.it \\ ${ }^{2}$ Department of Biology, Ecology and Earth Science (DiBEST), University of Calabria 87030, Italy - pietro.brandmayr@unical.it \\ * Corresponding author
}

\begin{abstract}
In carabid beetles, several morphometric parameters may vary from one habitat to another. Body size is one of the most important traits in animals because it directly relates to fitness and changes across latitudinal and altitudinal gradients. In this paper, we compare two populations of Nebria kratteri (Coleoptera, Carabidae) sampled in two old forest sites of the Sila Mountain in Calabria. The specimens show significant differences in all morphometric parameters measured, the larger size at one site could be related to intraspecific competition.
\end{abstract}

Key words: morphometry, carabids, body size, intraspecific competition.

\section{Introduction}

Ground beetles (Coleoptera: Carabidae) are frequently used as bioindicators (Kotze et al. 2011). These beetles respond to abiotic and biotic variation, and to disturbances and management (e.g. Lövei \& Sunderland 1996; Rainio $\&$ Niemelä 2003). These should reliably reflect particular environmental conditions. Although carabids have the potential to reflect soils, wetness and habitat-type variation (e.g. Thiele 1977; Lövei \& Sunderland 1996), they cannot currently compete with plants as indicators of these factors. Several parameters, from physiological processes to environmental pressures, play a role in determining the body size and related morphological parameters in insects (Wheeler 1996; Angilletta 2003). Most of these factors may vary from one habitat to another; at a large geographic scale, clinal variation of morphological parameters within species from different taxa has been found (Hallas 2002; Blanckenhorn 2004). Strong relationships exist between body size and a variety of physiological and ecological features, including metabolic rate, production rate, survival probability and the likelihood of dispersal (Bommarco 1998). Body size is one of the most important traits in animals because it directly relates to fitness. Body size variation research clarifies morphoadaptation of organisms to the environment changes and intra- and interpopulations relations, which cannot be revealed by other methods and do not yield to the experimental check
(Gelashvili et al. 2011; Talarico et al., 2007). Body size also changes across latitudinal and altitudinal gradients. However, in insect species, size does not vary regularly with elevation. Some species are larger at higher elevations (Stalker \& Carson 1948, Miller 1991, Hawkins \& Devries 1996, Krasnov et al. 1996), some smaller (Janes 1994; Hawkins \& Devries 1996; Sota 1996; Blanckenhorn 1997; Krasnov et al. 1996), and some show no change at all (Hawkins \& Devries 1996). Studies measuring body size, life-history characters, development, and population dynamics over a temperature gradient will assist in distinguishing the factors responsible for clinal variation among populations (Sukhodolskaya 2013, 2014). The aim of this work is to compare two populations of Nebria kratteri (Coleoptera, Carabidae) sampled in two old forest sites on the Sila Mountains: a) site "MO" (Macchia dell'Orso), fir dominated forest mixed with beech; b) site "S" (Spinalba Mount), beech forest mixed with silver fir. According to Magistretti (1965), in Calabria this species is found especially in mountain sites, including Sila and Pollino massifs. Nebria kratteri lives from the hills to the tree line, and has to be considered a purely forest species. The beetle represents a hygrophilic element, which concentrates at the edges of the waters, and is found up to $2000 \mathrm{~m}$ a.s.l., on dead leaves or wet parts of the forest. Diet of Nebria species includes collembola, small spiders and other invertebrates (Davies 1953).

Aim of this study is to clarify if body size and morpho- 
metric characteristics of an abundant forest species may vary also between two very similar although differently managed stands within a large forested landscape and what for factors may be responsible of the observed differences.

\section{Materials and Methods}

\section{The study sites}

The beetles samples have been collected in two forest sites of the inner part of the Sila National Park, both stands belong to the beech-silver fir mixed forest typical of the Southern Italian Apennine. Each site measured exactly one hectare and was carefully checked for structural and vegetation characteristics in the frame of the "Foreste Vetuste" project, an action plan promoted by the Italian Ministry for the Environment. The Spinalba forest was studied at 2017, Macchia dell'Orso during 2018, and in each site also ground beetles were sampled in four symmetrical subplots of the hectare. In all subplots two pitfall traps were active for an entire season (June/November), and the specimen counts are expressed in "annual activity density", i.e. individuals/trap in the standard period of ten days (mean values of the sampling period).

The most relevant features of the stands are summarized in Table 1, where also some characteristics of the carabid beetle community are reported.

\section{Beetles and measurements}

The samples consisted of 20 individuals of Nebria kratteri (ten males and ten females) for each sampling site. Specimens were collected in southern Italy (Calabria) from June 2017 to November 2018. For morphometric analyses, specimens stored in ethanol (70\%), were measured. Photographs were taken with a Zeiss Stemi SV 11Apo stereoscope and acquired by Matrox PC-VCR software. Body length, head width and length, eyes distance, thorax width and length, abdomen width, elytra width and length (right and left) were measured for each specimen. Measurements were taken using Sigma Scan Pro 5 Software (SPSS $\AA$ Inc.) and expressed as means \pm standard error. Sexual dimorphism in each species and morphological differences among species was tested using the Kruskal-Wallis test.

\section{Results and Discussion}

$N$. kratteri presents significant differences in sexual dimorphism for all parameters in both of the sampling sites (Table $2 ; \mathrm{p}<0.001)$. Significant differences have been found in body length, head length and width, eyes distance, abdomen length and width, elytra length and width, all values were larger in site $\mathrm{S}$ than in the site MO (Table 3; $\mathrm{p}<0.001)$. About weighted values, the right elytra is longer in samples from site $\mathrm{S}$ than in $\mathrm{MO}$ and thorax is longer in site MO than in S (Fig. 1). Morphometric data show that in the two sampled sites $N$. kratteri preserves its sexual dimorphism. This indicates a good site conservation condition. Specimens from the two sites show significant differences in some morphometric characteristics. In particular, the larger dimensions of of $N$. kratteri individuals from $\mathrm{S}$

Table 1 - Main characteristics of the two forest stands.

\begin{tabular}{l|l|l|}
\hline Forest denomination & Spinalba (lat 39 104247 - long 16 653505) & Macchia dell'Orso (lat 39 130220 - long 16 645935) \\
\hline Forest type & $\begin{array}{l}\text { Beech/silver fir mixed forest } \\
\text { (Ranunculo-Fagetum) }\end{array}$ & $\begin{array}{l}\text { Beech/silver fir mixed forest (Ranunculo- } \\
\text { Fagetum) with silver fir dominance in the canopy }\end{array}$ \\
\hline Altitude & $1700-1680 \mathrm{~m}$ & $1640-1620 \mathrm{~m}$ \\
Aspect & SW-SSE & S-SW \\
Slope & $5-10-20^{\circ}$ & $5-10-25^{\circ}$ \\
Canopy covering & $80-90-100 \%$ & $85-90-95 \%$ \\
Leaf litter depth/covering & $2-3 \mathrm{~cm} / 100 \%$ & $1-3 \mathrm{~cm} / 50-80-90 \%$ \\
Age of the silver fir & From $>200 \mathrm{y}$ (scattered plants) to 20-40 y & $80-90 \mathrm{y}$ \\
Age of the beech & From $70-80$ to $20-50 \mathrm{y}$ & From 70 to 30-35 y \\
Necromass $\%$ of dead wood on the soil) & $20-30-40 \%$, some old snags & $20-30 \%$ \\
Soil properties & Dystrudept, well drained & Dystrudept, humid \\
Nebria kratteri annual activity density & $4.225 \pm 0.767$ & $43.720 \pm 9.244$ \\
(mean SE of four subplots) & & Nebria kratteri \\
Dominant carabid at the site & Pterostichus bicolor amorei & 11 \\
N of carabid species at the site & 14 & Sporadic grazing \\
Disturbance & Moderate grazing by cows &
\end{tabular}


Table 2 - Morphometric differences (means and standard error of the mean) in N. kratteri male and female by the sites. Kruskal-Wallis chi-squared results are shown. Statistical significant results are in bold.

\begin{tabular}{|c|c|c|c|c|c|c|c|}
\hline \multirow[b]{2}{*}{ Measured } & \multicolumn{2}{|c|}{ Male } & \multicolumn{2}{|c|}{ Female } & \multirow[b]{2}{*}{$\begin{array}{l}\text { Kruskal-Wallis } \\
\text { chi-squared }\end{array}$} & \multirow[b]{2}{*}{ df } & \multirow[b]{2}{*}{ p-value } \\
\hline & Means & SEM & Means & SEM & & & \\
\hline \multicolumn{8}{|l|}{ MO site } \\
\hline Body length (mm) & 8.219 & 0.108 & 8.654 & 0.134 & 5.1429 & 1 & 0.02334 \\
\hline Head width (mm) & 1.668 & 0.018 & 1.714 & 0.030 & 0.75685 & 1 & 0.3843 \\
\hline Head length (mm) & 1.313 & 0.063 & 1.529 & 0.044 & 6.6057 & 1 & 0.01017 \\
\hline Eyes distance(mm) & 1.152 & 0.026 & 1.172 & 0.028 & 0.14286 & 1 & 0.7055 \\
\hline Thorax width (mm) & 2.511 & 0.030 & 2.516 & 0.035 & 0.035741 & 1 & 0.8501 \\
\hline Thorax length (mm) & 1.575 & 0.018 & 1.630 & 0.049 & 0.46321 & 1 & 0.4961 \\
\hline Abdomen width (mm) & 3.294 & 0.047 & 3.520 & 0.039 & 10.08 & 1 & 0.001499 \\
\hline Elytra width (R) (mm) & 1.548 & 0.039 & 1.675 & 0.035 & 4.8057 & 1 & 0.02837 \\
\hline Elytra width (L) (mm) & 1.611 & 0.029 & 1.725 & 0.037 & 4.1657 & 1 & 0.04125 \\
\hline Elytra length (R) (mm) & 4.796 & 0.075 & 5.203 & 0.078 & 9.3799 & 1 & 0.002194 \\
\hline Elytra length (L) (mm) & 4.711 & 0.061 & 5.121 & 0.089 & 9.1429 & 1 & 0.002497 \\
\hline Head width/ Body length & 0.203 & 0.002 & 0.198 & 0.002 & 4.1941 & 1 & 0.04056 \\
\hline Head length/Body length & 0.159 & 0.006 & 0.176 & 0.003 & 5.1701 & 1 & 0.02298 \\
\hline Thorax width/ Body length & 0.306 & 0.003 & 0.291 & 0.003 & 8.4891 & 1 & 0.003573 \\
\hline Thorax length/ Body length & 0.192 & 0.003 & 0.188 & 0.004 & 0.75857 & 1 & 0.3838 \\
\hline Elytra width (R)/ Body length & 0.188 & 0.004 & 0.194 & 0.004 & 1.2877 & 1 & 0.2565 \\
\hline Elytra length (L)/ Body length & 0.583 & 0.005 & 0.601 & 0.003 & 5.1701 & 1 & 0.02298 \\
\hline Eyes distance/ Head length & 0.893 & 0.041 & 0.770 & 0.023 & 4.48 & 1 & 0.03429 \\
\hline Eyes distance/Head width & 0.692 & 0.020 & 0.686 & 0.021 & 0.24179 & 1 & 0.6229 \\
\hline \multicolumn{8}{|l|}{ S site } \\
\hline Body length (mm) & 8.438 & 0.133 & 9.303 & 0.094 & 11.063 & 1 & 0.0008807 \\
\hline Head width (mm) & 1.735 & 0.025 & 1.832 & 0.018 & 6.2229 & 1 & 0.01261 \\
\hline Head length (mm) & 1.498 & 0.051 & 1.662 & 0.039 & 4.4834 & 1 & 0.03423 \\
\hline Eyes distance(mm) & 1.210 & 0.023 & 1.311 & 0.018 & 8.2576 & 1 & 0.004058 \\
\hline Thorax width (mm) & 2.487 & 0.041 & 2.616 & 0.028 & 5.1545 & 1 & 0.02319 \\
\hline Thorax length (mm) & 1.604 & 0.028 & 1.710 & 0.026 & 5.1429 & 1 & 0.02334 \\
\hline Abdomen width (mm) & 3.380 & 0.057 & 3.684 & 0.047 & 10.08 & 1 & 0.001499 \\
\hline Elytra width (R) (mm) & 1.804 & 0.030 & 1.959 & 0.031 & 7.2068 & 1 & 0.007263 \\
\hline Elytra width (L) (mm) & 1.709 & 0.043 & 1.933 & 0.026 & 11.063 & 1 & 0.0008807 \\
\hline Elytra length (R) (mm) & 5.049 & 0.064 & 5.428 & 0.081 & 7.8229 & 1 & 0.005159 \\
\hline Elytra length (L) (mm) & 5.132 & 0.081 & 5.477 & 0.074 & 7.8229 & 1 & 0.005159 \\
\hline Head width/ Body length & 0.206 & 0.001 & 0.197 & 0.001 & 11.598 & 1 & 0.0006604 \\
\hline Head length/Body length & 0.177 & 0.005 & 0.179 & 0.003 & 0.051506 & 1 & 0.8205 \\
\hline Thorax width/ Body length & 0.295 & 0.003 & 0.281 & 0.003 & 6.0539 & 1 & 0.01388 \\
\hline Thorax length/ Body length & 0.190 & 0.002 & 0.184 & 0.003 & 3.5903 & 1 & 0.05812 \\
\hline Elytra width (R)/ Body length & 0.214 & 0.002 & 0.211 & 0.003 & 0.0014405 & 1 & 0.9697 \\
\hline Elytra length (L)/ Body length & 0.599 & 0.006 & 0.583 & 0.007 & 3.0274 & 1 & 0.08187 \\
\hline Eyes distance/ Head length & 0.817 & 0.031 & 0.792 & 0.020 & 0.4639 & 1 & 0.4958 \\
\hline Eyes distance/Head width & 0.699 & 0.014 & 0.716 & 0.008 & 1.2041 & 1 & 0.2725 \\
\hline
\end{tabular}


Table 3 - Morphometric differences (means and standard error of the mean) in the species by the sites. Kruskal-Wallis chi-squared results are shown. Statistical significant results are in bold.

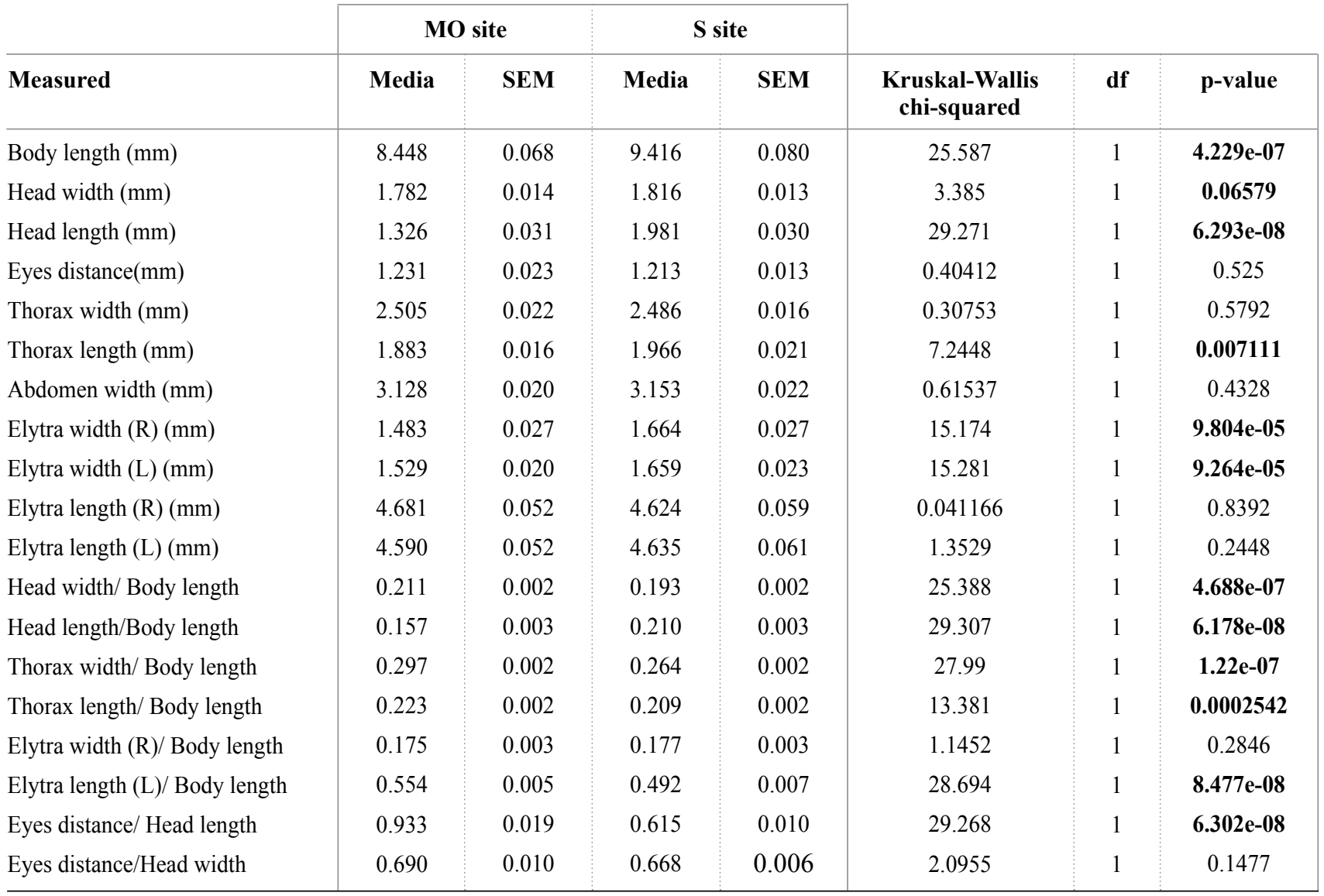

site compared with MO. Spinalba forest is a partially deciduous forest (beech forest) with scattered, very old silver fir giants, habitat conditions and trophic niches allow the presence of a higher number of carabid species. Macchia dell'Orso forest is largely dominated by fir and the soil is very humid and poor of understorey. The population density of $N$. kratteri in this second stand is extremely high; here Nebria dominates the community with a mean of 43.720 individuals/trap that is it shows a population density ten times higher than in Spinalba.

$N$. kratteri is a non-specialist predator of small size prey that live on the surface of the leaf litter. The larval stages appear in late autumn and are active also in the less cold winter months, searching for prey on the leaf litter. They belong to the morphological type of the "surface runner" (Zetto Brandmayr et al., 1998), thus they are unable to search for prey in the soil depth and are forced to compete with conspecific larvae on the leaf litter surface. This could be a possible explanation of the larger body size of the Spinalba population, favoured by a remarkably lower intraspecific competition.

Other possible explanations should anyway be considered. Disturbance is sometimes thought to influence body size of carabids. Blake et al. (1994) concluded that disturbed habitats support a carabid fauna of smaller average body size than do less disturbed habitats. Though almost no published information seems to exist about the importance of beech forest soil types and related vascular plant richness to carabid abundance and species richness, effects of vegetation structure and diversity have often been recognised under other field conditions (Bortmann 1996). It seems likely that body size variability is caused by differences in food availability during the larval stage. It was demonstrated that variable host size had a major influence on the body size of adults in the parasitic carabid Brachinus lateralis Dejean (Juliano 1985). The great body size fluctuations, particularly in males, of species belonging to the Lucanidae (e.g., Mizunuma \& Nagai 1994) are related both to differences in space and in nutrition during the long larval period. Indirect evidence of the importance of environmental conditions to the body size of imagines is the presence of very small-sized populations of some Carabus species, e.g. C. violaceus, in the far north of Europe, such as in montane and subarctic areas in northern Scandinavia (Sota et al. 2002). Carabids are mainly predators that feed on a wide variety of animals. Differenc- 
A

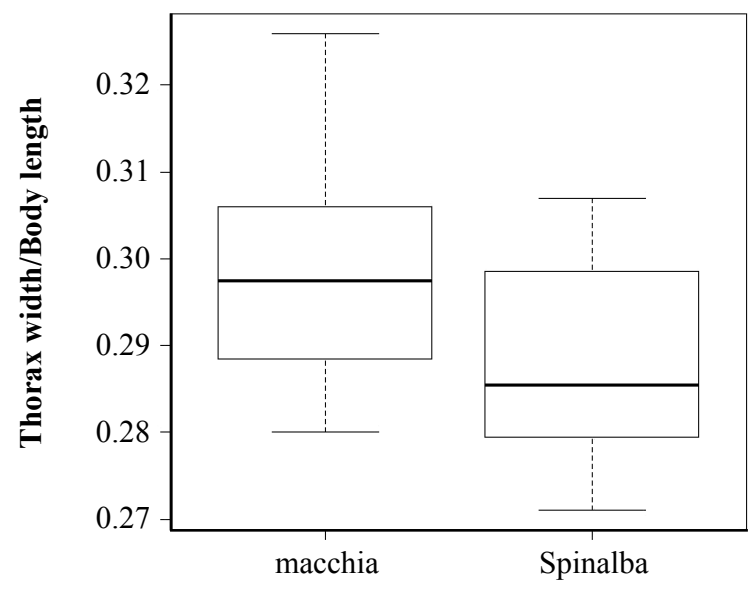

Sites
B

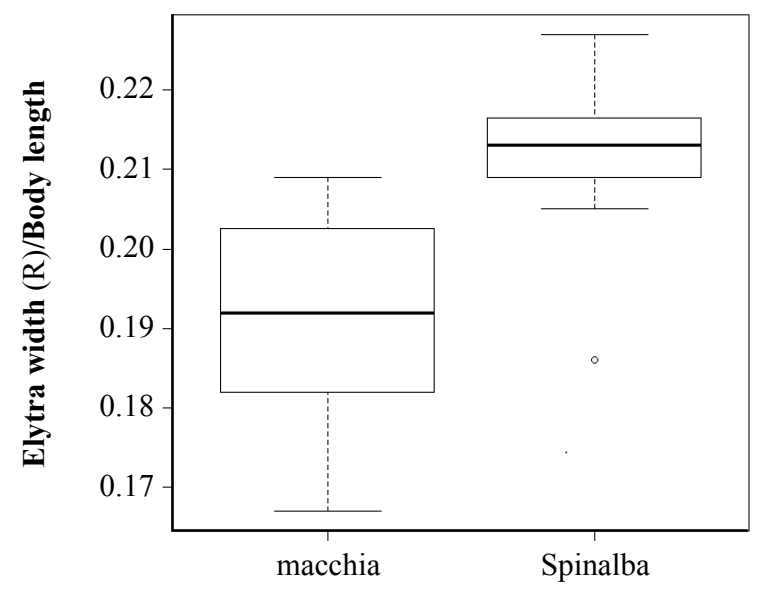

Sites

Fig. 1 - Measured traits: A) Thorax width/ Body length; B) Elytra width (R)/ Body length (mm) in the two species.

es in the composition, species richness, and other properties of the carabid beetle fauna between forests on contrasting soil types have little recognised. However, forests with canopies of the same dominating tree species, such as beech, may be characterized by widely differing properties, which is ought to exert to far-reaching influence on environmental conditions of importance to the carabid fauna (Tyler 2008). More investigations are needed but our results show remarkable differences in a carabid living in forest environments with different population density, different canopy and soil properties, and probable degrees of stability.

Acknowledgements - The authors are grateful to two thesis students, Pietro Russo and Daniel Jean Madej, for contributing to the paper. Research financed by the Sila National Park, project "Foreste Vetuste", 3rd phase. The authors are grateful to the Park Administration for permissions and financial help.

\section{References}

Angilletta J., Dunham A.E. 2003. The temperature-size rule in ectotherms: simple evolutionary explanations may not be general. American Naturalist, 162: 332-342.

Blake S., Foster G.N., Eyre M.D., Luff M.L. 1994. Effects of habitat type and grassland management practices on the body size distribution of carabid beetles. Pedobiologia, 38: 502512.

Blanckenhorn W.U. 1997. Altitudinal life history variation in the dung flies Scathophaga stercoraria and Sepsis cynipsea. Oecologia, 109: 342-352.

Blanckenhorn W.U., Demont M. 2004. Bergmann and Converse Bergmann Latitudinal Clines in Arthropods: Two Ends of a Continuum. Integrative Comparative Biology, 44: 413-424.

Bommarco R. 1998. Reproduction and energy reserves of a predatory carabid beetle relative to the Agroecosystem complexity. Ecological Applications, 8(3): 846-853.
Bortmann I., 1996. Heterogenitäten der Besiedlung durch Laufkäfer (Col.: Carabidae) in einem Buchenwald. Faunistisch-Ökologische Mitteilungen (Suppl. 22), 87-126.

Davies M.I. 1953. Crop contents of some British Carabids. Entomologists' Monthly Magazine 89: 18-23.

Gelashvili D.B., Soltzev L. A., Yakimov V.N., Sukhodolskaya R.A., Khabibullina N.R., Iudin D.I., Snegiryova M.S. 2011. Fractal analysis of the specific structure of Carabidae complexes in urbanized territories. Povolzhskiy Journal of Ecology, 4: 407-420 [in Russian].

Hallas R., Schiffer M., Hoffmann A.A. 2002. Clinal variation in Drosophila serrata for stress resistance and body size. Genetics Research, 79: 53.

Hawkins B.A., Devries P.J. 1996. Altitudinal gradients in the body size of Costa Rican butterflies. Acta Oecologica, 17: 185-194.

Janes S.W. 1994. Variation in species composition and mean body size of an avian foliage-gleaning guild along an elevational gradient: correlation with arthropod body size. Oecologia, 98: 369-378.

Juliano S.A. 1985. The effects of body size on mating and reproduction in Brachinus lateralis (Coleoptera: Carabidae). Ecological Entomology, 10: 271-280.

Kotze D.J., Brandmayr P., Casale A., Dauffy-Richard E., Dekoninck W., Koivula M. J., Loevei G.L., Mossakowski D., Noordijk J., Paarmann W., Pizzolotto R., Saska P., Schwerk A., Serrano J., Szyszko J., Taboada A., Turin H., Venn S., Vermeulen R., Zetto T. 2011. Forty years of carabid beetle research in Europe - from taxonomy, biology, ecology and population studies to bioindication, habitat assessment and conservation. Zookeys, 100: 55-148.

Krasnov B., Ward D., Shenbrot G. 1996. Body size and leg length variation in several species of darkling beetles (Coleoptera: Tenebrionidae) along a rainfall and altitudinal gradient in the Negev Desert (Israel). Journal of Arid Environments, 34: 477-489.

Lovei G.L., Sunderland K.D. 1996. Ecology and behaviour of ground beetles (Coleoptera: Carabidae). Annual Review of Entomology, 41: 231-256.

Magistretti M. 1965. Fauna D'Italia. Coleoptera, Cicindelidae. Carabidae- Vol. VIII. Catalogo topografico, Calderini, Bologna. 
Miller W.E. 1991. Positive relation between body size and altitude of capture site in tortricid moths (Tortricidae). Journal of the Lepidopterists' Society, 45: 66-67.

Mizunuma T., Nagai S. 1994. The lucanid beetles of the world. Mushi-Sha's Iconographic Series of Insects 1, Tokyo, 338 pp.

Rainio J., Niemelä J. 2003. Ground beetles (Coleoptera: Carabidae) as bioindicators. Biodiversity and Conservation, 12: 487-506.

Sota T. 1996. Altitudinal variation in life cycles of carabid beetles: life-cycle strategy and colonization of alpine zone. Arctic and Alpine Research, 28: 441-447.

Sota T., Takami Y., Kubota K., Ishikawa R. 2002. Geographic variation in body size of carabid beetles: patterns resulting from climatic adaptation and interspecific interaction. Japanese Journal of Entomology (New Series), 5: 88-97 [in Japanese, English Abstract].

Stalker H.D., Carson H.L. 1948. An altitudinal transect of Drosophila robusta Sturtevant. Evolution, 2: 295-305.

Sukhodolskaya R. 2014. Variation in body size and body shape in ground beetle Pterostichus melanarius Ill. (Coleoptera, Carabidae). Journal of Agri-Food and Applied Sciences, 2(7): 196-205.

Sukhodolskaya R.A., Eremeeva N.I. 2013. Body size and shape variation in Ground Beetle Carabus aeruginosus F.-W., 1822 (Coleoptera, Carabidae). Contemporary Problems of Ecology, 6(6): 609-615.

Talarico F., Romeo M., Massolo A., Brandmayr P., Zetto T. 2007. Morphometry and eye morphology in three species of Carabus (Coleptera: Carabidae) in relation to habitat demands. Journal of Zoological Systematics and Evolutionary Research, 45(1): 33-38.

Thiele H.U. 1977. Carabid Beetles in their Environments (369 pp.). Berlin: Springer.

Tyler G. 2008. Differences in abundance, species richness, and body size of ground beetles (Coleoptera: Carabidae) between beech (Fagus sylvatica L.) forests on Podzol and Cambisol. Forest Ecology and Management, 256: 2154-2159.

Wheeler D. 1996. The role of nourishment in oogenesis. Annual Review of Entomology, 41: 407-431. 